\title{
The Parasite of Society: Food and Class Studies in Bong Joon-ho's Parasite
}

\author{
Emily Turner, Ball State University
}

The role that food plays in film typically has more meaning than a viewer might realize at first. Often viewers watch movies for entertainment without analyzing the context that the food in each scene provides to the richness of the plot. For example, Bong Joon-ho's 2019 award-winning film Parasite thrills its audience while warning them about the dangers of capitalism and class disparity. Despite the popularity of this film, the aspect of food was quietly forgotten even though it enhances the movie's theme. Bong intentionally placed food in this film to signify class status, which further divides the Park and Kim families. While this is a critically-acclaimed film, there is not much scholarship devoted to food studies, concerning social class in Parasite; therefore, I am drawing upon movie reviews as well as scholarly work about food in media. In doing this, I have studied Parasite through lenses of socioeconomic theory as well as food theory to analyze how food is used in the film. Food involves more than simply preparing ingredients and consuming the final product, especially when used in media and popular culture: it often provides deeper meaning that must be examined in order to know what is truly being said. In the film Parasite, food is the vehicle that Bong uses to signify social status, and furthermore, it signals class disparities between the wealthy and impoverished. Beyond the film, Bong uses food to warn his audience how class inequality could be the downfall, the parasite, of society.
Food studies in media provide complex layers to the films that viewers quite literally consume, a fact complicated depending on how one analyzes food. Different theories, lenses, and contexts can change how food is used in film, much like how using different ingredients in a recipe can alter the final product. But why does food matter in film, and how do directors use food to create meaning? Food is often employed to symbolize greater significance or to prove a point that a director wants to assert in their film. For example, Bong Joon-ho's film Parasite (2019) utilizes food to symbolize social class: food is a vehicle in this film to show both the stark divide between the upper and lower classes and how such economic disparity can be perilous for society. Bong does this to warn viewers that class inequality is unjust by demonstrating how greed within different social classes warrants grave consequences. Ultimately, Parasite concludes with the patriarch of the ultra-wealthy Park family deceased while the extremely impoverished Kim family is divided, still dangerously poor, and suffering the death of their daughter/sister. While these may be extreme conclusions to draw from the film, Parasite aims to warn its viewers of the greed between social classes that could lead to such dismal ends. Bong accomplishes this through the placement of food: it symbolizes the class divide that each family struggles with in different ways. 
Although Parasite is a critically-acclaimed film, due to its newness, there is not much scholarship devoted to it; therefore, my essay draws from film reviews, socio-economic and food theories, and scholarly work about food and media in order to show how Parasite uses food to elucidate class inequality that threatens dire ramifications for the whole of society. Food involves more than simply preparing ingredients and consuming the final product, especially when employed in media and popular culture. In Parasite, food is the vehicle that Bong utilizes to signify social status, and furthermore, class disparities between the wealthy and impoverished. Such class disparity - the struggle over wealth and resources-beckons the collapse of society as the rich become richer and the poor become poorer until society can no longer withstand the pressure of the parasitic relationship that capitalism fosters.

In the film, viewers are first introduced to the Kim family: they are living in a crowded basement, and it becomes obvious from the clothes they wear, their lack of Wi-Fi connection, and their living situation that they are impoverished. The Kim family is always in need of work, so when Ki-woo, the son, tricks his way into tutoring the daughter of the wealthy Park family, the Kims take extreme measures to infiltrate the Park household for employment through various means. The Parks are oblivious to the Kims' schemes - they are blissfully unaware since they rely so heavily on the employment of the lower class to maintain their homelife. However, their ambient relationship turns parasitic once the Parks' old employees threaten to reveal that the Kims have been scamming the Parks for work. The Kims will do anything to keep their jobs, including murder, but the struggle over power and wealth comes to a head when chaos unfolds at the end of the film due to the parasitic relationship that each family cultivates. Bong leaves the viewers questioning the inner workings of capitalism and class inequality as they reflect on which family was the true antagonist, or parasite, of the film.

Bong portrays the class divide between the Kim and Park families in a variety of ways, including their homes, lifestyles, levels of education, and hygiene. For example, the Park family lives in a pristine, well-kept mansion while the Kim family lives in a crowded, dirty basement. Yet, when we consider food theory in cinema, it becomes clear that food in Parasite is a key mechanism through which Bong critiques class exploitation. Anne Bower and Thomas Piontek explain that "[t]hroughout cinematic history, food has played a part in all kinds of films, frequently revealing aspects of characters' emotions, identities, cultural backgrounds, fears, and inspirations" (177). Food in Parasite acts as a vehicle to explore not only the families' socio-economic statuses but also the sheer divide between the two, which is why the film ends with death and despair. The Park family consumes food out of luxury while the Kim family consumes and uses food out of necessity: this demonstrates how each family operates within their respective social classes. Hojin Song explains how food studies can be used to identify systems within media: "Through identifying and studying food categories, it is possible to decode the religious, political, economic, social, and cultural systems in which food and food-centered practices are embedded" (5). Song's ideology can be used to analyze the food in Parasite as social and economic mechanisms, like how food and consumption denotes a class divide between the two families, ultimately pushing each family to collapse. While the Parks consume in excess, the Kims consume the bare minimum due to their poverty, which promotes the greed that causes them to infiltrate the Parks' lavish homelife. Bong's employment of food to denote social status is particularly striking because food is needed to survive. Access to food should be a given right; however, Parasite highlights how this is not true among the 
impoverished. While the Parks have fully stocked fridges and pantries as well as a maid to prepare their every meal, the Kims must buy and consume food from vending machines. Food is not guaranteed for the Kim family. In other words, any scene that contains food and drink in Parasite, whether it be ramdon or alcohol, signifies either economic distress or excess, suggesting that too much or too little of something-money, food, etc.—can be fatally dangerous, promoting the parasitic relationship of the rich profiting from the poor.

Although the Kim and Park families are starkly different, they act like symbiotics, sucking the life out of one another, to survive. Put another way, the way in which each family prepares and consumes food symbolizes the class divide as well as how each family needs each other to live. The Kim mother, Choong-sook, must prepare meals for the Park family as Yeon-kyo, the Park mother, does not have the capability to do similar tasks for her family on her own. Due to her wealth and status, Yeon-kyo never needed to learn how to cook or clean; therefore, she, as well as her family, are reliant on Chong-sook. Observer film critic Mark Kermode defines this relationship in his review as "[a] lifestyle that relies upon hired help: tutors, a chauffeur and, most importantly, a devoted housekeeper Moon-gwang (Lee Jung-eun), who stayed with the building after its original architect owner moved out". The Kim family disposes of Moon-gwang by exposing her to peaches, which she is allergic to, in order for Chong-sook to take over as the Parks' maid. Food here is used as a weapon; while the peach itself may not symbolize economic inequality, it does show the desperation of the Kims to infiltrate the Park family for their money. The Kim family is so poor that they feel the need to endanger Moon-gwang so they can be paid in her place. Weaponizing food thus reflects the wealth gap that causes the Kim family to go through such great lengths to acquire wealth. Through the disposal of Moon-gwang, Choong-sook is able to become the new maid, which allows the viewers to see Chong-sook preparing food for the Kims. Even though the Parks could not produce their own meals without Chong-sook, the Kim family would not be able to buy their food without the money they receive from the Parks. Bong utilizes this symbiotic symbolism, from production to consumption of food within the two families, to highlight the downfalls of capitalism. Neither the rich nor the poor can survive without each other, but to do so, the impoverished must suffer while the rich profits from such suffering. Bong's portrayal of food preparation and consumption in this film signifies such a divide between the two families and beyond them, concerning the wealthy upper class versus the impoverished lower class. Parasite implies that without remedying class disparity, society will inevitably fail under the strain of greed caused by capitalism.

Despite being the poorest of the poor, working for an elite family can include certain advantages, though such benefits can come at a grave cost. While the Park family is away on a camping trip for their son's birthday, the Kims sneak into the Parks' mansion to indulge in their employers' riches through the consumption of alcohol, which leaves the family intoxicated. They drink in excess because consuming alcohol is a luxury that they cannot afford to enjoy due to their poor circumstances. French essayist and theorist Roland Barthes posits in his book Mythologies that "[d]rinking is felt as the exposure of pleasure, not as the necessary cause of a sought-for effect: wine is not only a philter but also a durational act of drinking: the gesture here has a decorative value, and wine's power is never separated from its modes of existence" (80). Here, Barthes is discussing wine; however, one can come to a similar conclusion within this scene even though the Kim family consumes liquor as opposed to wine. Both wine and

9 | Turner 
liquor are alcoholic beverages that lead to drunkenness when overconsumed. While the Parks use expensive liquor for decorative value, they are never shown drinking to become drunk. The Kims, however, manipulate the Parks' wealth in order to drink for pleasure-a luxury. They invade their employers' mansion while it is vacant, but they also invade the family's lifestyle, feeding off of what the Kims could never obtain without the Park family. Alcohol in this scene is a mode for transformation as well as escapism for the Kim family: in doing so they are not only breaking and entering, but also stealing. Viewers might resent the Kims for stealing what is not theirs, or they might empathize with the family who is too poor to afford life's necessities, let alone life's luxuries. Whether or not viewers support or chastise the Kims in this scene, alcohol is a mechanism for morality: "Wine thus provides a collective morality, within which everything is redeemed: excesses, disasters, crimes are of course possible with wine, but not wickedness, perfidy, or ugliness; the evil it can engender is in the nature of fate and therefore escapes penalization, it is a theatrical evil, not a temperamental one" (Barthes 81). Barthes claims that under the influence of alcohol, one can be immoral but not wicked, so while watching this scene in Parasite, one must ask themselves: are the Kims simply immoral, or are they committing evil acts? Gluttony is a transgression; however, it feels impossible for the Kim family to be gluttonous, even when they are drinking in excess, due to their poverty. Conversely, the Parks overconsume on a daily basis because of their wealth. It is immoral to break and enter. It is immoral to steal. But it is also immoral to be complacently rich in a society where the destitute struggle to provide for themselves day in and day out. Through alcohol, Bong highlights this question of morality that forces viewers to think critically about the economic inequality caused by capitalism. The alcohol scene thus marks the beginning of the end for the Park and Kim family, mirroring the downfall of society once it, too, inevitably fails.

Bong uses the alcohol scene to depict the Kims as the luxurious, decadent family, but all illusions are suspended when Yeon-kyo calls Chong-sook, who is supposed to be home to house-sit, to inform her that they are coming home early from their camping trip due to bad weather. Film critic Manohla Dargis from The New York Times summarizes what is at stake during this scene: "By that point, you are as comfortably settled in as the Kims; the house is so very pleasant, after all. But the cost of that comfort and those pretty rooms - and the eager acquiescence to the unfairness and meanness they signify-comes at a terrible price." Here, Dargis refers to how certain aspects of capitalism have severe consequences as seen in the film. One scene in particular demonstrates the fatal class divide between the Park and Kim families via the production of food: when Yeon-kyo is on the phone with Chong-sook, she asks that Chong-sook prepares ram-don for the family to eat when they arrive home. Ram-don is a popular Korean dish that is quick and easy to make on a budget, which is why it is so shocking to the Kim family when Yeon-kyo requests that Chong-sook adds premium beef on top of the ram-don noodles. Viewers who are unfamiliar with this dish might compare the oddness of the request to putting high quality steak on top of macaroni and cheese prepared from a box. Evelyn Yang provides further context to Yeon-kyo's request by observing that "[t]o add a steak on top of the cheap instant noodles is an act of qualifying and justifying Mrs. Park's enjoyment of a 'lower-class' dish. The rich, despite their wealth, would still crave for things that are below their social status, but with their own imagination." One can infer from Yang that although the wealthy can relate to the poor by craving a cheap dish, they can never close the gap between social classes that capitalism established; Yeon-kyo cannot consume ram-don on its own, for it 
must include wealthy ingredients such as premium beef. Bernice Chan and Alkira Reinfrank, writers and reporters for the South China Morning Post, describe how Yeon-kyo's request demonstrates how far removed the wealthy is from the rest of society: "This is meant to be a sign of how outlandishly rich these people are and how out of touch they are from what normal people eat." Therefore, Yeon-kyo's request for a cheap dish (despite the addition of steak) is also used for irony since she craves a dish typically reserved for those who cannot afford higher quality food. As soon as Yeon-kyo hangs up the phone, chaos ensues as the Kim family rushes to erase any signs that they have intruded before the Parks' return home. The premium ram-don and the Kims' panicked response after Yeon-kyo's call represents how each family cannot belong in the opposite social class, showing division among the families due to the wealth gap.

The struggle for power and wealth between the Park and Kim families comes to a climax, resulting in bloodshed, trauma, and death. Yeon-kyo throws an elaborate birthday party for her son Da-song, the youngest member of the Park family, that includes copious amounts of consumption fit for all the wealthy partygoers. They even watch a performance that mocks marginalized people (Indigenous Americans), showing how superior the wealthy believe they are compared to other groups: at the apex of the film, Bong blatantly demonstrates how he thinks the wealthy dehumanize those who are poor or marginalized. The party ends horrifically when Geun-sae, another impoverished captive of capitalism, escapes his confines and stabs Ki-jung, the daughter of the Kim family. Geun-sae is Moon-gwang's husband, who she has hidden in the depths of the Park mansion so that she could provide for him via the Parks' wealth-another symbiotic relationship. Due to his devotion to the Parks, as well as being mentally unstable because of the isolation, Geun-sae escapes the basement and kills Ki-jung. Food, then, is an enabler for Geun-sae because without the Parks' food and shelter, he would have never survived poverty. In the end, both families suffer from loss and severe trauma, which Bong uses to signify how the overconsumption of wealth and resources proves to be fatal to both the upper and lower class, causing the eventual collapse of society. Hence, the Kims' and Parks' relationship evolves from symbiosis to parasitism as the Kims' infiltration leads to the deaths and/or injury of members of each family. Korean cinema researcher Christina Klein contends that "Korean cinema allows us to think about the global circulation of U.S. popular culture in a more comprehensive way" (24-25). Bong utilizes the party scene to take an inward look at Korean social class disparity to then look outward in order to perceive how other capitalistic economies face the same struggles that viewers see in Parasite. Beyond the film, viewers must realize that unequal distribution, or hoarding, of wealth and resources destroys societies from within, much like how a parasite overtakes its host. Bong's use of food in this film is poignant as it is the vehicle to promote this anti-capitalistic message. By the end of the party scene, Chong-sook fatally stabs Geun-sae with a kabob stick, which symbolizes how even the poor are pitted against each other in the ever-lasting struggle for control over wealth. Yang summarizes that "[Bong] witnesses the story of Parasite every day in a capitalist society. Living in a world where capitalism dominates our values, where we celebrate our freedoms of choices, our wealth and quality of life are more polarized than ever." Food placement is essential for the analysis of the party scene as what began with the overconsumption of food ends with bloodshed. Here, Bong employs food to encapsulate the theme of his film: class divides promote the rich to benefit from the poor's suffering before ultimately collapsing. Both the Kim and Park families experience great loss by the end of the party scene, showing how their parasitic relationship that mimics the 11 | Turner 
downfalls of capitalism festers and dies, much like how food inevitably rots and decomposes until it is nothing at all.

Bong utilizes food in Parasite to highlight the danger and greed that promotes class inequality within capitalistic economies. Through what each family consumes, Bong shows the scarcity of wealth and resources of the Kim family and the hoarding of the same items from the Park family. Furthermore, the Kims use food as a weapon and a luxury, which shows their desperation for wealth, while the Parks use food for comfort and decorative purposes. Although Parasite concludes with extreme consequences, it is simply warning viewers to take a critical look inwards at how their economy operates to create class inequality. Food studies in this film provide rich and complex meaning beyond the overlying message that Bong aims to promote: Bong intentionally placed food in Parasite to define the capitalistic structures that extend the gap between the rich and the poor. In the film, food symbolizes how greed and class disparity will ultimately cause the collapse of society. Bong accomplishes this throughout the duration of the film, but his point is made evident at the end of the party scene wherein each family suffers injury, trauma, and death, demonstrating that capitalism is detrimental to every social class whether it be families as poor or as rich as the Kims and Parks. Food preparation, delivery, and consumption in Parasite shows that such distress and disparity among social classes lead to perilous ends to everyone within that society. 
Barthes, Roland. "Wine and Milk." Mythologies. Bréal, 2009, pp. 79-82.

Bower, Anne, and Thomas Piontek. "Food in Film." Routledge International Handbook of Food Studies, doi:10.4324/9780203819227.ch16.

Chan, Bernice, and Alkira Reinfrank. "Those Ram-Don Noodles from Parasite: A Cheap Noodle Treat Popular with Students and Not Usually found on Restaurant Menus: South Korean Film Parasite's Win at this Year's Oscars also made a Global Star Out of an Elevated Snack Food Classic. Anyone for Ram-Don?" South China Morning Post, 26 June 2020, www.scmp.com/life style/food-drink/article/3090342/those-ram-don-noodles-parasite-cheap-noodle-treat-popular.

Dargis, Manohla. "'Parasite' Review: The Lower Depths Rise With a Vengeance." The New York Times, The New York Times, 10 Oct. 2019, www.nytimes.com/2019/10/10/movies/parasite-review.html.

Bong, Joon-ho. Parasite. Neon, 2019.

Kermode, Mark. "Parasite Review - a Gasp-Inducing Masterpiece." The Guardian, Guardian News and Media, 10 Feb. 2020, www.theguardian.com/film/2020/feb/09/parasite-re view-bong-joon-ho-tragicomic-masterpiece.

Klein, Christina. "Why American Studies Needs to Think about Korean Cinema, or, Transnational Genres in the Films of Bong Joon-Ho." American Quarterly, vol. 60, no. 4, 2008, pp. 871-898.

Song, Hojin. "South Korean Food and Women in Glocalization: A Case Study in the Role of Food Media," ProQuest Dissertations Publishing, 2016.

Yang, Evelyn. "Parasite' Symbolism Explained: Instant Noodles, Language, Basement." The News Lens International Edition, 15 Feb. 2020, www.international.thenewslens.com/article/131297. 